\title{
Common fixed points for pairs of triangular $\alpha$-admissible mappings
}

\author{
Haitham Qawagneh ${ }^{\mathrm{a}, *}$, Mohd Salmi MD Noorani ${ }^{\mathrm{a}}$, Wasfi Shatanawi ${ }^{\mathrm{b}, \mathrm{c}}$, Habes Alsamir ${ }^{\mathrm{d}}$ \\ a School of mathematical Sciences, Faculty of Science and Technology, University Kebangsaan Malaysia, 43600 UKM, Selangor Darul \\ Ehsan, Malaysia. \\ ${ }^{b}$ Department of Mathematics and General Courses, Prince Sultan University, Riyadh, Saudi Arabia. \\ ${ }^{c}$ Department of Mathematics, Hashemite University, Zarqa, Jordan. \\ ${ }^{d}$ Department of Mathematics and General Courses, Aljouf University, Aljouf, Saudi Arabia.
}

Communicated by N. Hussain

\begin{abstract}
In this paper, we introduce the notation of $(\alpha-\eta)-(\psi-\varphi)$-contraction mappings defined on a set X. We prove the existence of common fixed point results for the pair of self-mappings involving C-class functions in the setting of metric space. Our results generalize and extend several works existing in literature. We provide an example and some applications in order to support our results. (C)2017 All rights reserved.
\end{abstract}

Keywords: C-class functions, $\alpha$-admissible mapping, common fixed point, metric spaces.

2010 MSC: 47H09, 47H10.

\section{Introduction}

The techniques of fixed point theory have been applicable in some fields such as Biology, Physics, Economics, Engineering and Game Theory. Several mathematicians have been generalized fixed point theory in multi-directions. One of the most important tools in fixed point theory is the Banach contraction principle, a lot of authors extended and generalized the Banach contraction principle to many directions (for example see [3, 6, 12, 15, 17-19]). Samet et al. [17] introduced the concept of $\alpha-\psi$-contractive type mapping and they utilized their new concept to establish and proved many fixed point theorems. After that several authors used the concept of $\alpha$-admissible mappings to demonstrate new results in many spaces (see [2, 7, 9, 11, 12, 14, 16, 17]). In 2013, Salimi et al. [16] modified the concept of $\alpha-\psi$-contractive type mapping and established fixed point results in metric space. Recently, Hussain et al. [9] proved some fixed point results for single and multi-valued $\alpha-\eta-\psi$-contractive type mapping in complete metric space. Very recently, Ansari and Kaewcharoen [5] introduced a new type of contraction based on $\alpha$-admissible with respect to another function $\eta$ and proved some fixed point theorems of such mappings.

Samet et al. [17] presented the concept of $\alpha$-admissible mappings as the following:

\footnotetext{
*Corresponding author

Email addresses: haitham.math77@gmail.com (Haitham Qawagneh), msn@ukm.my (Mohd Salmi MD Noorani), wshatanawi@psu.edu.sa, swasfi@hu.edu.jo, wshatanawi@yahoo.com (Wasfi Shatanawi), h.alsamer@gmail.com (Habes Alsamir) 
Definition 1.1 ([17]). Let $f: X \rightarrow X$ and $\alpha: X \times X \rightarrow[0, \infty)$. Then $f$ is called $\alpha$-admissible if for all $x, y \in X$ with $\alpha(x, y) \geqslant 1$ implies $\alpha(f x, f y) \geqslant 1$.

Definition 1.2 ([11]). Let $T: X \rightarrow X$ and $\alpha: X \times X \rightarrow[0, \infty)$. Then $T$ is called a triangular $\alpha$-admissible Mapping if

1. $T$ is $\alpha$-admissible;

2. $\alpha(x, z) \geqslant 1$ and $\alpha(z, y) \geqslant 1$ imply $\alpha(x, y) \geqslant 1$.

In 2014, Ansari [4] defined the concept of C-class function as the following:

Definition $1.3([4])$. A mapping $F:[0,+\infty) \times[0,+\infty) \rightarrow \mathbb{R}$ is called a C-class function if it is continuous and for $s, t \in[0, \infty), F$ satisfies the following two conditions:

1. $F(s, t) \leqslant s ;$ and

2. $F(s, t)=s$ implies that either $s=0$ or $t=0$.

The family of all C-class functions is denoted by $\mathcal{C}$.

Example 1.4 ([4]). The following functions $\mathrm{F}:[0,+\infty) \times[0,+\infty) \rightarrow \mathbb{R}$ are elements in $\mathrm{C}$.

1. $F(s, t)=s-t$ for all $s, t \in[0, \infty)$.

2. $F(s, t)=k s$ for all $s, t \in[0, \infty)$, where $0<k<1$.

3. $F(s, t)=\frac{s}{(1+t)^{r}}$ for all $s, t \in[0, \infty)$, where $r \in[0, \infty)$.

4. $F(s, t)=(s+l)^{\left(1 /(1+t)^{r}\right)}-l$ for all $s, t \in[0, \infty)$, where $r \in(0, \infty), l>1$.

5. $F(s, t)=s \log _{t+a} a$ for all $s, t \in[0, \infty)$, where $a>1$.

6. $F(s, t)=s-\left(\frac{1+s}{2+s}\right)\left(\frac{t}{1+t}\right)$ for all $s, t \in[0, \infty)$.

7. $F(s, t)=s \beta(s)$ for all $s, t \in[0, \infty)$, where $\beta:[0, \infty) \rightarrow[0,1)$ is continuous.

8. $F(s, t)=s-\varphi(s)$ for all $s, t \in[0, \infty)$, where $\varphi:[0, \infty) \rightarrow[0, \infty)$ is a continuous function such that $\varphi(t)=0$ if and only if $t=0$.

9. $F(s, t)=\operatorname{sh}(s, t)$ for all $s, t \in[0, \infty)$, where $h:[0, \infty) \times[0, \infty) \rightarrow[0, \infty)$ is a continuous function such that $h(s, t)<1$ for all $s, t \in[0, \infty)$.

10. $F(s, t)=s-\left(\frac{2+t}{1+t}\right) t$ for all $s, t \in[0, \infty)$.

11. $F(s, t)=\sqrt[\mathfrak{n}]{\ln \left(1+s^{\mathfrak{n}}\right)}$ for all $s, t \in[0, \infty)$.

In 2016, Ansari and Kaewcharoen [5] gave the definition of a generalized $\alpha-\eta-\psi-\varphi-F$-contraction type mapping and proved same fixed point theorems for such mappings in complete metric spaces.

Definition 1.5 ([5]). Let $(X, d)$ be a metric space and $\alpha, \eta: X \times X \rightarrow[0, \infty)$ be two functions. A mapping $\mathrm{T}: \mathrm{X} \rightarrow \mathrm{X}$ is said to be a generalized $\alpha-\eta-\psi-\varphi-$ F-contraction type mapping if $\alpha(x, y) \geqslant \eta(x, y)$ implies

$$
\psi(d(T x, T y)) \leqslant F(\psi(M(x, y)), \varphi(M(x, y))),
$$

where

$$
M(x, y)=\max \{d(x, y), d(x, T x), d(y, T y)\}
$$

Hussain et al. [8] introduced the concepts of $\alpha-\eta$-complete metric spaces and $\alpha-\eta$-continuous functions.

Definition 1.6 ([8]). Let $(X, d)$ be a metric space and $\alpha, \eta: X \times X \rightarrow[0, \infty)$ be two functions. Then $X$ is said to be an $\alpha, \eta$-complete metric space if every Cauchy sequence $\left\{x_{n}\right\}$ in $X$ with $\alpha\left(x_{n}, x_{n+1}\right) \geqslant \eta\left(x_{n}, x_{n+1}\right)$ for all $n \in \mathbb{N}$ converges in $X$.

Definition $1.7([8])$. Let $(X, d)$ be a metric space and $\alpha, \eta: X \times X \rightarrow[0, \infty)$ be two functions. A mapping $\mathrm{T}: X \rightarrow X$ is said to be an $\alpha, \eta$-continuous mapping if each sequence $\left\{x_{n}\right\}$ in $X$ with $x_{n} \rightarrow x$ as $n \rightarrow \infty$ and $\alpha\left(x_{n}, x_{n+1}\right) \geqslant \eta\left(x_{n}, x_{n+1}\right)$ for all $n \in \mathbb{N}$ implies $T x_{n} \rightarrow T x$ as $n \rightarrow \infty$. 
Theorem $1.8([5])$. Let $(X, d)$ be a metric space. Assume that $\alpha, \eta: X \times X \rightarrow[0, \infty)$ are two functions and $\mathrm{T}: \mathrm{X} \rightarrow \mathrm{X}$ is a mapping. Suppose that the following conditions are satisfied:

1. $(\mathrm{X}, \mathrm{d})$ is an $\alpha, \eta$-complete metric space;

2. $\mathrm{T}$ is generalized $\alpha-\eta-\psi-\varphi-\mathrm{F}$-contraction type mapping;

3. $\mathrm{T}$ is triangular $\alpha$-orbital admissible mapping with respect to $\eta$;

4. there exist $x_{1} \in X$ such that $\alpha\left(x_{1}, T x_{1}\right) \geqslant \eta\left(x_{1}, T x_{1}\right)$;

5. $T$ is an $\alpha, \eta$-continuous mapping.

Then $T$ has a fixed point $x^{*} \in X$.

Moreover, many authors utilized the C-class functions in several spaces to obtain many interesting results. For more details see $[2,7,9,11,14,16]$.

Lemma 1.9 ([1]). Suppose that $(X, d)$ is a metric space and $\left\{x_{n}\right\}$ is a sequence in $X$ such that $\mathrm{d}\left(x_{n}, x_{n+1}\right) \rightarrow 0$ as $n \rightarrow \infty$. If $\left\{x_{n}\right\}$ is not a Cauchy sequence, then there exist $a n \in>0$ and sequences of positive integers $\{m(k)\}$ and $\{\mathrm{n}(\mathrm{k})\}$ with $\mathrm{m}(\mathrm{k})>\mathrm{n}(\mathrm{k})>\mathrm{k}$ such that $\mathrm{d}\left(\mathrm{x}_{\mathrm{m}(\mathrm{k})}, \mathrm{x}_{\mathrm{n}(\mathrm{k})}\right) \geqslant \epsilon, \mathrm{d}\left(\mathrm{x}_{\mathrm{m}(\mathrm{k})-1}, \mathrm{x}_{\mathrm{n}(\mathrm{k})}\right)<\epsilon$ and

1. $\lim _{k \rightarrow \infty} d\left(x_{m(k)}, x_{n(k)}\right)=0$;

2. $\lim _{k \rightarrow \infty} d\left(x_{m(k)-1}, x_{n(k)}\right)=0$;

3. $\lim _{k \rightarrow \infty} d\left(x_{m}(k), x_{n}(k)-1\right)=0$.

Khan et al. [13] introduced the notion of an altering distance function as follows:

Definition $1.10([13])$. A mapping $\psi:[0,+\infty) \rightarrow[0,+\infty)$ is called an altering distance function if the following properties are satisfied:

1. $\psi$ is monotone and nondecreasing;

2. $\psi(t)=0$ if and only if $t=0$.

The set of all altering distance functions is denoted by $\Psi$. In the rest of this paper, we set $\Phi=\{\varphi$ : $[0,+\infty) \rightarrow[0,+\infty)$ is continuous and $\varphi(t)=0 \Leftrightarrow t=0\}$.

\section{Main result}

In this section, we introduce the concept of a triangular $\alpha$-admissible mapping with respect to $\eta$ and we prove the existence of common fixed point results on $\alpha-\eta$-complete metric space for generalized F-contraction.

We start our work by introducing the notion of triangular $\alpha$-admissible for pair of self-mappings $T$ and $S$ on a set $X$.

Definition 2.1. Let $S, T: X \rightarrow X$ be two mappings and $\alpha: X \times X \rightarrow[0,+\infty)$ be a function such that the following conditions hold:

1. if $\alpha(x, y) \geqslant 1$, then $\alpha(S x, T y) \geqslant 1$ and $\alpha(T S x, S T y) \geqslant 1$;

2. if $\alpha(x, z) \geqslant 1$ and $\alpha(z, y) \geqslant 1$, then $\alpha(x, y) \geqslant 1$.

Then we say that the pair $(S, T)$ is triangular $\alpha$-admissible.

Now, we introduce the notion of triangular $\alpha$-admissible with respect to another function $\eta$ for the pair of self-mappings $S$ and $T$ on a set $X$.

Definition 2.2. Let $S, T: X \rightarrow X$ be two mappings and $\alpha, \eta: X \times X \rightarrow[0,+\infty)$ be two functions such that the following conditions hold:

1. if $\alpha(x, y) \geqslant \eta(x, y)$, then $\alpha(S x, T y) \geqslant \eta(S x, T y)$ and $\alpha(T S x, S T y) \geqslant \eta(T S x, S T y)$; 
2. if $\alpha(x, z) \geqslant \eta(x, z)$ and $\alpha(z, y) \geqslant \eta(z, y)$, then $\alpha(x, y) \geqslant \eta(x, y)$.

Then we say that the pair $(S, T)$ is triangular $\alpha$-admissible with respect to $\eta$.

Now, we introduce the following example to illustrate our new definition.

Example 2.3. Let $X=[0,+\infty)$. Define $S, T: X \rightarrow X$ by $S x=x, T x=x^{2}$. Also, definition the functions $\alpha, \eta: X \times X \rightarrow[0,+\infty)$ by $\alpha(x, y)=e^{x+y}$ and $\eta(x, y)=e^{y-x}$. Then the pair $(S, T)$ is triangular $\alpha-$ admissible with respect to $\eta$.

Proof. If $\alpha(x, y) \geqslant \eta(x, y)$, then $e^{x+y} \geqslant e^{y-x}$. So $x+y \geqslant y-x$. So $2 x \geqslant 0$. Hence $x \geqslant 0$. Since $x \geqslant-x$, then $x+y^{2} \geqslant y^{2}-x$. So $e^{x+y^{2}} \geqslant e^{y^{2}-x}$. Hence $\alpha\left(x, y^{2}\right) \geqslant \eta\left(x, y^{2}\right)$. So $\alpha(S x, T y) \geqslant \eta(S x, T y)$. Also, since $x^{2} \geqslant-x^{2}$, then $x^{2}+y^{2} \geqslant y^{2}-x^{2}$. So $e^{x^{2}+y^{2}} \geqslant e^{y^{2}-x^{2}}$. Hence $\alpha\left(x^{2}, y^{2}\right) \geqslant \eta\left(x^{2}, y^{2}\right)$. So $\alpha(T S x, S T y) \geqslant \eta(T S x, S T y)$. Also, if $\alpha(x, z) \geqslant \eta(x, z)$, and $\alpha(z, y) \geqslant \eta(z, y)$, then $x+z \geqslant z-x$ and $z+y \geqslant y-z$. So, $x \geqslant-x$ and hence $x+y \geqslant y-x$. Then $e^{x+y} \geqslant e^{y-x}$. Therefore $\alpha(x, y) \geqslant \eta(x, y)$.

The following lemma will be helpful for us to achieve our main results.

Lemma 2.4. Let $S, T: X \rightarrow X$ be two mappings and $\alpha, \eta: X \times X \rightarrow[0,+\infty)$ be two functions such that the pair $(\mathrm{S}, \mathrm{T})$ is triangular $\alpha$-admissible with respect to $\eta$. Assume that there exist $\mathrm{x}_{0} \in \mathrm{X}$ such that $\alpha\left(\mathrm{x}_{0}, \mathrm{~S} \mathrm{x}_{0}\right) \geqslant$ $\eta\left(x_{0}, S x_{0}\right)$. Define a sequence $\left\{x_{n}\right\}$ in $X$ by $S x_{2 n}=x_{2 n+1}$ and $T x_{2 n+1}=x_{2 n+2}$. Then $\alpha\left(x_{n}, x_{m}\right) \geqslant \eta\left(x_{n}, S x_{m}\right)$ for all $\mathrm{m}, \mathrm{n} \in \mathbb{N}$ with $\mathrm{n}<\mathrm{m}$.

Proof. Since $\alpha\left(x_{0}, S x_{0}\right) \geqslant 1$ and $S, T$ are $\alpha$-admissible, we get

$$
\alpha\left(x_{0}, x_{1}\right)=\alpha\left(x_{0}, S x_{0}\right) \geqslant \eta\left(x_{0}, S x_{0}\right) .
$$

By triangular $\alpha$-admissibility, we get

$$
\alpha\left(S x_{0}, T x_{1}\right)=\alpha\left(x_{1}, x_{2}\right) \geqslant \eta\left(x_{1}, S x_{2}\right)
$$

and

$$
\alpha\left(\mathrm{TSx}_{0}, \mathrm{ST} \mathrm{x}_{1}\right)=\alpha\left(\mathrm{x}_{2}, \mathrm{x}_{3}\right) \geqslant \eta\left(\mathrm{x}_{2}, \mathrm{~S} \mathrm{x}_{3}\right) .
$$

Again, since $\alpha\left(x_{2}, x_{3}\right) \geqslant \eta\left(x_{2}, S x_{3}\right)$, then

$$
\alpha\left(S x_{2}, T x_{3}\right)=\alpha\left(x_{3}, x_{4}\right) \geqslant \eta\left(S x_{2}, T x_{3}\right)=\eta\left(x_{3}, S x_{4}\right)
$$

and

$$
\alpha\left(\mathrm{TSx}_{2}, \mathrm{ST} x_{3}\right)=\alpha\left(x_{4}, \mathrm{~S} x_{5}\right) \geqslant \eta\left(\mathrm{TS} x_{2}, \mathrm{ST} x_{3}\right)=\eta\left(x_{4}, S x_{5}\right) .
$$

By continuing the above process, we conclude that $\alpha\left(x_{n}, x_{n+1}\right) \geqslant \eta\left(x_{n}, x_{n+1}\right)$ for all $n \in \mathbb{N} \cup\{0\}$.

Now, we prove that $\alpha\left(x_{n}, x_{m}\right) \geqslant \eta\left(x_{n}, x_{m}\right)$, for all $m, n \in \mathbb{N}$ with $n<m$. Given $m, n \in \mathbb{N}$ with $n<m$. Since

$$
\left\{\alpha\left(x_{m}, x_{m+1}\right) \geqslant \eta\left(x_{m}, x_{m+1}\right), \alpha\left(x_{m+1}, x_{m+2}\right) \geqslant \eta\left(x_{m+1}, x_{m+2}\right),\right.
$$

then, we have

$$
\alpha\left(x_{m}, x_{m+2}\right) \geqslant \eta\left(x_{m}, x_{m+2}\right) .
$$

Again, since

$$
\left\{\begin{array}{l}
\alpha\left(x_{m}, x_{m+2}\right) \geqslant \eta\left(x_{m}, x_{m+2}\right), \\
\alpha\left(x_{m+2}, x_{m+3}\right) \geqslant \eta\left(x_{m+2}, x_{m+3}\right),
\end{array}\right.
$$

we deduce that

$$
\alpha\left(x_{m}, x_{m+3}\right) \geqslant \eta\left(x_{m}, x_{m+3}\right) .
$$

By continuing this process, we have

$$
\alpha\left(x_{n}, x_{m}\right) \geqslant \eta\left(x_{n}, x_{m}\right) \forall n \in \mathbb{N} \text { with } m>n .
$$


Let $S, T$ be two self-mappings on a set $X$. In the rest of this paper, we let

$$
M^{*}(x, y)=\max \{d(x, y), d(x, S x), d(y, T y)\}
$$

In order to facilitate our subsequent arguments, we introduce the notion of generalized F-contraction for a pair of self-mappings $S, T$ on a set $X$.

Definition 2.5. Let $(X, d)$ be a metric space, $T, S: X \rightarrow X$ be two mappings and $\alpha, \eta: X \times X \rightarrow \mathbb{R}$ be two functions. Let $F \in \mathcal{C}, \psi \in \Psi$ and $\varphi \in \Phi$. Then the pair $(S, T)$ is called generalized F-contraction if $\alpha(x, y) \geqslant \eta(x, y)$, then

$$
\psi(d(S x, T y)) \leqslant F\left(\psi\left(M^{*}(x, y)\right), \varphi\left(M^{*}(x, y)\right)\right) .
$$

Theorem 2.6. Let $(\mathrm{X}, \mathrm{d})$ be a metric space and $\mathrm{S}, \mathrm{T}$ be two self-mappings on $\mathrm{X}$. Assume that $\alpha, \eta: \mathrm{X} \times \mathrm{X} \rightarrow[0,+\infty)$ are two functions. Suppose that the following conditions hold:

1. $(\mathrm{X}, \mathrm{d})$ is an $\alpha, \eta$-complete metric space.

2. $(\mathrm{S}, \mathrm{T})$ is generalized F-contraction.

3. $(S, T)$ is triangular $\alpha$-admissible with respect to $\eta$.

4. There exists $\mathrm{x}_{0} \in \mathrm{X}$ such that $\alpha\left(\mathrm{x}_{0}, \mathrm{~S} \mathrm{x}_{0}\right) \geqslant \eta\left(\mathrm{x}_{0}, S \mathrm{x}_{0}\right)$.

5. $S$ and $T$ are $\alpha, \eta$-continuous mappings.

Then $(\mathrm{S}, \mathrm{T})$ have a common fixed point.

Proof. We present our proof in three steps:

Step 1. Let $x_{0} \in X$ be such that $\alpha\left(x_{0}, S x_{0}\right) \geqslant \eta\left(x_{0}, S x_{0}\right)$. Define a sequence $\left\{x_{n}\right\}$ in $X$ such that $x_{2 n+1}=S x_{2 n}$ and $x_{2 n+2}=T x_{2 n+1}$ for all $n \in \mathbb{N}$. If $x_{n_{0}}=x_{n_{0}+1}$ for some $n_{0} \in \mathbb{N}$, then it is very easy to show that $S$ and $T$ have a common fixed point. Now, since the pair $(S, T)$ is $\alpha$-admissible with respect to $\eta$, then

$$
\alpha\left(x_{1}, x_{2}\right)=\alpha\left(S x_{0}, T x_{1}\right) \geqslant \eta\left(S x_{0}, T x_{1}\right)=\eta\left(x_{1}, x_{2}\right)
$$

and

$$
\alpha\left(x_{2}, x_{1}\right)=\alpha\left(T x_{1}, S x_{0}\right) \geqslant \eta\left(T x_{1}, S x_{0}\right)=\eta\left(x_{2}, x_{1}\right) .
$$

Again, by using $\alpha$-admissible property with respect to $\eta$, we have

$$
\alpha\left(x_{2}, x_{3}\right)=\alpha\left(T x_{1}, S x_{2}\right) \geqslant \eta\left(T x_{1}, S x_{2}\right)=\eta\left(x_{2}, x_{3}\right)
$$

and

$$
\alpha\left(x_{3}, x_{2}\right)=\alpha\left(S x_{2}, T x_{1}\right) \geqslant \eta\left(S x_{2}, T x_{1}\right)=\eta\left(x_{3}, x_{2}\right) .
$$

Repeating the above process for $n$-times, we have $\alpha\left(x_{n}, x_{n+1}\right) \geqslant \eta\left(x_{n}, x_{n+1}\right)$ and $\alpha\left(x_{n+1}, x_{n}\right) \geqslant \eta\left(x_{n+1}, x_{n}\right)$. Using the property of triangular $\alpha$-admissibility with respect to $\eta$, we can deduce that for any $n, m \in \mathbb{N}$ with $m>n$, we have $\alpha\left(x_{n}, x_{m}\right) \geqslant \eta\left(x_{n}, x_{m}\right)$ and $\alpha\left(x_{m}, x_{n}\right) \geqslant \eta\left(x_{m}, x_{n}\right)$.

Suppose $x_{2 n} \neq x_{2 n+1}$ for all $n \in \mathbb{N}$, by Lemma 2.4, we have $\alpha\left(x_{2 n}, x_{2 n+1}\right) \geqslant \eta\left(x_{2 n}, x_{2 n+1}\right)$ for all $n \in \mathbb{N}$. Since $(S, T)$ is a generalized F-contraction mapping, we have

$$
\begin{aligned}
\psi\left(d\left(x_{2 n+1}, x_{2 n+2}\right)\right) & =\psi\left(d\left(S x_{2 n}, T x_{2 n+1}\right)\right) \\
& \leqslant F\left(\psi\left(M^{*}\left(x_{2 n}, x_{2 n+1}\right)\right), \varphi\left(M^{*}\left(x_{2 n}, x_{2 n+1}\right)\right)\right) \\
& \leqslant \psi\left(M^{*}\left(x_{2 n}, x_{2 n+1}\right)\right)
\end{aligned}
$$

for all $n \in \mathbb{N}$, where

$$
\begin{aligned}
M^{*}\left(x_{2 n}, x_{2 n+1}\right) & =\max \left\{d\left(x_{2 n}, x_{2 n+1}\right), d\left(x_{2 n}, S x_{2 n}\right), d\left(x_{2 n+1}, T x_{2 n+1}\right)\right\} \\
& =\max \left\{d\left(x_{2 n}, x_{2 n+1}\right), d\left(x_{2 n}, x_{2 n+1}\right), d\left(x_{2 n+1}, x_{2 n+2}\right)\right\}
\end{aligned}
$$




$$
=\max \left\{d\left(x_{2 n}, x_{2 n+1}\right), d\left(x_{2 n+1}, x_{2 n+2}\right)\right\} \text {. }
$$

If $M^{*}\left(x_{2 n}, x_{2 n+1}\right)=d\left(x_{2 n+1}, x_{2 n+2}\right)$, then

$$
\begin{aligned}
\psi\left(d\left(x_{2 n+1}, x_{2 n+2}\right)\right) & \leqslant F\left(\psi\left(M^{*}\left(x_{2 n}, x_{2 n+1}\right)\right), \varphi\left(M^{*}\left(x_{2 n}, x_{2 n+1}\right)\right)\right) \\
& \leqslant \psi\left(M^{*}\left(x_{2 n}, x_{2 n+1}\right)\right) \\
& \leqslant \psi\left(d\left(x_{2 n}, x_{2 n+1}\right)\right)
\end{aligned}
$$

Since $x_{2 n} \neq x_{2 n+1}$ for all $n \in \mathbb{N}$, and $\psi \in \Psi, \varphi \in \Phi$, we have $\psi\left(d\left(x_{2 n}, x_{2 n+1}\right)\right) \neq 0$ and $\varphi\left(d\left(x_{2 n}, x_{2 n+1}\right)\right) \neq$ 0 . According to the definition of a C-class function, we conclude that

$$
\psi\left(d\left(x_{2 n+1}, x_{2 n+2}\right)\right)<\psi\left(d\left(x_{2 n}, x_{2 n+1}\right)\right),
$$

which is a contradiction. Thus we conclude that

$$
M^{*}\left(x_{2 n}, x_{2 n+1}\right)=d\left(x_{2 n}, x_{2 n+1}\right) .
$$

By (2.1) and (2.2), we get $\psi\left(d\left(x_{2 n+1}, x_{2 n+2}\right)\right) \leqslant \psi\left(d\left(x_{2 n}, x_{2 n+1}\right)\right)$ for all $n \in \mathbb{N}$. Since $\psi$ is nondecreasing, we have $d\left(x_{2 n+1}, x_{2 n+2}\right) \leqslant d\left(x_{2 n}, x_{2 n+1}\right)$ for all $n \in \mathbb{N}$.

Similarly, we can show that $d\left(x_{2 n}, x_{2 n+1}\right) \leqslant d\left(x_{2 n-1}, x_{2 n}\right)$. So, we conclude that $d\left(x_{n}, x_{n+1}\right) \leqslant$ $d\left(x_{n-1}, x_{n}\right)$ for all $n \in \mathbb{N} \cup\{0\}$. It follow that the sequence $\left\{d\left(x_{n}, x_{n+1}\right)\right\}$ is non-increasing for all $n \in \mathbb{N}$. Therefore there exists $r \geqslant 0$ such that $\lim _{n \rightarrow \infty} d\left(x_{n}, x_{n+1}\right)=r$. We claim that $r=0$. Now, we have

$$
\psi\left(d\left(x_{n+1}, x_{n+2}\right)\right) \leqslant F\left(\psi\left(d\left(x_{n}, x_{n+1}\right)\right), \varphi\left(d\left(x_{n}, x_{n+1}\right)\right)\right) .
$$

Taking $n \rightarrow \infty$, we obtain that

$$
\psi(r) \leqslant F(\psi(r), \varphi(r)) .
$$

This implies that $\psi(r)=0$ or $\varphi(r)=0$ which yields

$$
\lim _{n \rightarrow \infty} d\left(x_{n}, x_{n+1}\right)=0 .
$$

Step 2. To prove that $\left\{x_{n}\right\}$ is a Cauchy sequence by Lemma 1.9, there exist $\epsilon>0$ and two subsequences $\left\{x_{m(k)}\right\}$ and $\left\{x_{n(k)}\right\}$ of $\left\{x_{n}\right\}$ with $m_{k}>n_{k}>k$ such that:

$$
d\left(x_{n(k)}, x_{m(k)}\right) \geqslant \epsilon, d\left(x_{n(k)}, x_{m(k)-1}\right)<\epsilon .
$$

Then, using the triangular inequality we get

$$
\begin{aligned}
\epsilon & \leqslant d\left(x_{n(k)}, x_{m(k)}\right) \leqslant d\left(x_{n(k)}, x_{m(k)-1}\right)+d\left(x_{m(k)-1}, x_{m(k)}\right) \\
& <\epsilon+d\left(x_{m(k)-1}, x_{m(k)}\right) .
\end{aligned}
$$

Taking $k \rightarrow \infty$ in the above inequality and using (2.3), we get

$$
\lim _{k \rightarrow \infty} d\left(x_{n(k)}, x_{m(k)}\right)=\epsilon .
$$

Since

$$
\left|\mathrm{d}\left(x_{n(k)}, x_{m(k)-1}\right)-d\left(x_{n(k)}, x_{m(k)}\right)\right| \leqslant d\left(x_{m(k)}, x_{m(k)-1}\right),
$$

we have $\lim _{k \rightarrow \infty} d\left(x_{n(k)}, x_{m(k)-1}\right)=\epsilon$. Similarly, we obtain that

$$
\lim _{k \rightarrow \infty} d\left(x_{n(k)}, x_{m(k)-1}\right)=\lim _{k \rightarrow \infty} d\left(x_{n(k)-1}, x_{m(k)-1}\right)=\epsilon .
$$

Given $n(k), m(k) \in \mathbb{N}$ with $m(k)>n(k)$. We will take four cases. 
Case $I: n(k)$ is odd and $m(k)$ is even. Here, $n(k)=2 k+1$ and $m(k)=2 k+s+1$ for some $k, s \in \mathbb{N}$, where $s$ is odd. Since $\alpha\left(x_{2 k+1}, x_{2 k+1+s}\right) \geqslant \eta\left(x_{2 k+1}, x_{2 k+1+s}\right)$ and by Lemma 2.4, we conclude that

$$
\begin{aligned}
\psi\left(d\left(x_{n(k)}, x_{m(k)}\right)\right) & =\psi\left(d\left(S x_{n(k)-1}, T x_{m(k)-1}\right)\right) \\
& =\psi\left(d\left(S x_{2 k}, T x_{2 k+s}\right)\right) \\
& \leqslant F\left(\psi\left(M^{*}\left(x_{2 k}, x_{2 k+s}\right)\right), \varphi\left(M^{*}\left(x_{2 k}, x_{2 k+s}\right)\right)\right)
\end{aligned}
$$

where

$$
\begin{aligned}
M^{*}\left(x_{2 k}, x_{2 k+s}\right) & =\max \left\{d\left(x_{2 k}, x_{2 k+s}\right), d\left(x_{2 k}, S x_{2 k}\right), d\left(x_{2 k+s}, T x_{2 k+s}\right)\right\} \\
& =\max \left\{d\left(x_{2 k}, x_{2 k+s}\right), d\left(x_{2 k}, x_{2 k+1}\right), d\left(x_{2 k+s}, x_{2 k+s+1}\right)\right\}
\end{aligned}
$$

So

$$
\lim _{n \rightarrow \infty} M^{*}\left(x_{2 k}, x_{2 k+s}\right)=\epsilon
$$

By (2.4) and (2.5), we have

$$
\psi(\epsilon) \leqslant \mathrm{F}(\psi(\epsilon), \varphi(\epsilon)) .
$$

It follows that $\psi(\epsilon)=0$ or $\varphi(\epsilon)=0$. So $\epsilon=0$ which is a contradiction. Thus $\left\{x_{n}\right\}$ is a Cauchy sequence.

Case II $: \mathfrak{n}(k)$ and $m(k)$ are both odd. By triangular inequality, we have

$$
d\left(x_{n(k)}, x_{m(k)}\right) \leqslant d\left(x_{n(k)}, x_{m(k)-1}\right)+d\left(x_{m(k)-1}, x_{m(k)}\right) .
$$

Letting $n(k), m(k) \rightarrow+\infty$ in above inequality and by using Case I, we get

$$
\lim _{n(k), m(k) \rightarrow+\infty} M^{*}\left(x_{n(k)}, x_{m(k)}\right)=\epsilon .
$$

We have $\psi(\epsilon) \leqslant F(\psi(\epsilon), \varphi(\epsilon))$. It follows that $\psi(\epsilon)=0$ or $\varphi(\epsilon)=0$.

Case III $: n$ and $m$ are both even. By triangular inequality, we have

$$
d\left(x_{n(k)}, x_{m(k)}\right) \leqslant d\left(x_{n(k)}, x_{n(k)+1}\right)+d\left(x_{n(k)+1}, x_{m(k)}\right) .
$$

Letting $n(k), m(k) \rightarrow+\infty$ in above inequality and by using Case I, we get

$$
\lim _{n(k), m(k) \rightarrow+\infty} M^{*}\left(x_{n(k)}, x_{m(k)}\right)=\epsilon .
$$

We have $\psi(\epsilon) \leqslant F(\psi(\epsilon), \varphi(\epsilon))$. It follows that $\psi(\epsilon)=0$ or $\varphi(\epsilon)=0$.

Case IV $: n$ is even and $m$ is odd. By triangular inequality, we have

$$
d\left(x_{n(k)}, x_{m(k)}\right) \leqslant d\left(x_{n(k)}, x_{n(k)+1}\right)+d\left(x_{n(k)+1}, x_{m(k)-1}\right)+d\left(x_{m(k-1}, x_{m(k)}\right)=0 .
$$

Letting $n(k), m(k) \rightarrow+\infty$ in above inequality and by using Case I, we get

$$
\lim _{n(k), m(k) \rightarrow+\infty} M^{*}\left(x_{n(k)}, x_{m(k)}\right)=\epsilon .
$$

We have $\psi(\epsilon) \leqslant F(\psi(\epsilon), \varphi(\epsilon))$. It follows that $\psi(\epsilon)=0$ or $\varphi(\epsilon)=0$.

Combining all cases together, we conclude that $\left(x_{n}\right)$ is a Cauchy sequence in $X$.

Step 3. We now prove that $S$ and $T$ have a common fixed point.

Since $\left\{x_{n}\right\}$ is a Cauchy sequence in the $\alpha, \eta$-complete metric space $X$, then there exists $x^{*} \in X$ such 
that $x_{n} \rightarrow x^{*}$. Since $S, T$ are $\alpha, \eta$-continuous mappings, we get $S x_{2 n} \rightarrow S x^{*}$ and $T x_{2 n+1} \rightarrow T x^{*}$. Since $x_{2 n+1}=S x_{2 n}$ and $x_{2 n+1} \rightarrow x^{*}$, by uniqueness of limit, we get

$$
\mathrm{S} x^{*}=x^{*}
$$

Again, Since $x_{2 n+2}=T x_{2 n+1}$ and $x_{2 n+2} \rightarrow x^{*}$, by uniqueness of limit, we get

$$
\mathrm{T} x^{*}=x^{*}
$$

So $x^{*}$ is a common fixed point of $S$ and $T$.

The continuity of $S$ and $T$ in Theorem 2.6 can be dropped if we replace condition(5) by suitable condition.

Theorem 2.7. Let $(\mathrm{X}, \mathrm{d})$ be a complete metric space and $\mathrm{S}, \mathrm{T}$ be two self-mappings on $\mathrm{X}$. Assume that $\alpha, \eta$ : $\mathrm{X} \times \mathrm{X} \rightarrow[0, \infty)$ are two function. Suppose that the following conditions are satisfied:

1. $(\mathrm{X}, \mathrm{d})$ is an $\alpha, \eta$-complete metric space.

2. $(\mathrm{S}, \mathrm{T})$ is generalized F-contraction.

3. $(S, T)$ is triangular $\alpha$-admissible respect to $\eta$.

4. There exists $\mathrm{x}_{0} \in \mathrm{X}$ such that $\alpha\left(\mathrm{x}_{0}, \mathrm{~S} \mathrm{x}_{0}\right) \geqslant \eta\left(\mathrm{x}_{0}, S \mathrm{x}_{0}\right)$.

5. If $\left\{x_{n}\right\}$ is a sequence in $X$ such that $\alpha\left(x_{n}, x_{n+1}\right) \geqslant \eta\left(x_{n}, x_{n+1}\right)$ for all $n \in N$ and $x_{n} \rightarrow x^{*} \in X$ as $n \rightarrow \infty$, then there exist a subsequence $\left\{x_{n(k)}\right\}$ of $\left\{x_{n}\right\}$ such that $\alpha\left(x_{n(k)}, x^{*}\right) \geqslant \eta\left(x_{n(k)}, x^{*}\right)$ for all $k \in \mathbb{N}$.

Then $\mathrm{S}$ and $\mathrm{T}$ have a common fixed point.

Proof. By using the proof of Theorem 2.6, we can construct a sequence $\left\{x_{n}\right\}$ in $X$ which is defined by $x_{2 n+1}=S x_{2 n}$ and $x_{2 n+2}=T x_{2 n+1}$ for all $n \in \mathbb{N}$ converging to $x^{*} \in X$ such that $\alpha\left(x_{n}, x_{n+1}\right) \geqslant \eta\left(x_{n}, x_{n+1}\right)$ for all $n \in \mathbb{N}$. By condition(5), there exist a subsequence $\left\{x_{n(k)}\right\}$ of $\left\{x_{n}\right\}$ such that $\alpha\left(x_{n(k)}, x^{*}\right) \geqslant$ $\eta\left(x_{n(k)}, x^{*}\right)$ for all $k \in \mathbb{N}$. Therefore,

$$
\begin{aligned}
\psi\left(d\left(x_{2 n(k)+1}, T x^{*}\right)\right) & =\psi\left(d\left(S x_{2 n(k)}, T x^{*}\right)\right) \\
& \leqslant F\left(\psi\left(M^{*}\left(x_{2 n(k)}, x^{*}\right)\right), \varphi\left(M^{*}\left(x_{2 n(k)}, x^{*}\right)\right)\right)
\end{aligned}
$$

for all $n \in \mathbb{N}$. Now,

$$
\begin{aligned}
M^{*}\left(x_{2 n(k)}, x^{*}\right) & =\max \left\{d\left(2 x_{n}, x^{*}\right), d\left(x_{2 n(k)}, S x_{2 n(k)}\right), d\left(x^{*}, T x^{*}\right)\right\} \\
& =\max \left\{d\left(x_{2 n(k)}, x^{*}\right), d\left(x_{2 n(k)}, x_{2 n(k)+1}\right), d\left(x^{*}, T x^{*}\right)\right\} .
\end{aligned}
$$

By taking $n \rightarrow \infty$ in (2.6) and using (2.3), we obtain

$$
\psi\left(d\left(x^{*}, T x^{*}\right)\right) \leqslant F\left(\psi\left(d\left(x^{*}, T x^{*}\right)\right), \phi\left(d\left(x^{*}, T x^{*}\right)\right)\right),
$$

which implies that $d\left(x^{*}, T x^{*}\right)=0$, that is, $T x^{*}=x^{*}$. By the same way we can show that $S x^{*}=x^{*}$.

Next, we introduced some corollaries:

Corollary 2.8. Let $(\mathrm{X}, \mathrm{d})$ be a complete metric space and $\mathrm{S}, \mathrm{T}$ be self-mappings on $\mathrm{X}$. Assume that $\alpha: \mathrm{X} \times \mathrm{X} \rightarrow \mathbb{R}$ is a function. Suppose that the following conditions hold:

1. If $\alpha(x, y) \geqslant 1$, then $\psi(d(S x, T x)) \leqslant F\left(\psi\left(M^{*}(x, y)\right), \varphi\left(M^{*}(x, y)\right)\right)$.

2. The pair $(\mathrm{S}, \mathrm{T})$ is triangular $\alpha$-admissible.

3. There exists $\mathrm{x}_{0} \in \mathrm{X}$ such that $\alpha\left(\mathrm{x}_{0}, \mathrm{~S} \mathrm{x}_{0}\right) \geqslant 1$.

4. $S$ and $T$ are $\alpha$-continuous mappings. 
Then $\mathrm{S}$ and $\mathrm{T}$ have a common fixed point.

Proof. The proof follows from Theorem 2.6 by defining $\eta: X \times X \rightarrow \mathbb{R}$ via $\eta(x, y)=1$.

Corollary 2.9. Let $(\mathrm{X}, \mathrm{d})$ be a complete metric space and $\mathrm{T}$ be a self-mapping on $\mathrm{X}$. Assume that $\alpha: \mathrm{X} \times \mathrm{X} \rightarrow[0, \infty)$ is a function. Suppose that the following conditions hold:

1. If $\alpha(x, y) \geqslant 1$, then $\psi(d(T x, T x)) \leqslant F\left(\psi\left(M^{*}(x, y)\right), \varphi\left(M^{*}(x, y)\right)\right)$, where

$$
M^{*}(x, y)=\max \{d(x, y), d(x, T x), d(y, T y)\}
$$

2. T is triangular $\alpha$-admissible.

3. There exists $\mathrm{x}_{0} \in \mathrm{X}$ such that $\alpha\left(\mathrm{x}_{0}, T \mathrm{x}_{0}\right) \geqslant 1$.

4. $\mathrm{T}$ is an $\alpha$-continuous mapping.

Then $\mathrm{T}$ has a fixed point.

Proof. The proof follows from Corollary 2.8 by taking $S=T$ and in this case noting that $M^{*}(x, y)=$ $M(x, y)$.

Corollary 2.10. Let $(\mathrm{X}, \mathrm{d})$ be a complete metric space and $\mathrm{S}, \mathrm{T}$ be self-mappings on $\mathrm{X}$. Assume that $\alpha: \mathrm{X} \times \mathrm{X} \rightarrow$ $[0, \infty)$ is a function. Suppose that the following conditions hold:

1. If $\alpha(x, y) \geqslant 1$, then $\psi(d(S x, T y)) \leqslant F\left(\psi\left(M^{*}(x, y)\right), \varphi\left(M^{*}(x, y)\right)\right)$.

2. The pair $(\mathrm{S}, \mathrm{T})$ is triangular $\alpha$-admissible.

3. There exists $\mathrm{x}_{0} \in \mathrm{X}$ such that $\alpha\left(\mathrm{x}_{0}, \mathrm{~S} \mathrm{x}_{0}\right) \geqslant 1$.

4. If $\left\{x_{n}\right\}$ is a sequence in $X$ such that $\alpha\left(x_{n}, x_{n+1}\right) \geqslant 1$ for all $n \in N$ and $x_{n} \rightarrow x^{*}$ as $n \rightarrow \infty$, there exist a subsequence $\left\{x_{n(k)}\right\}$ of $\left\{x_{n}\right\}$ such that $\alpha\left(x_{n(k)}, x^{*}\right) \geqslant 1$ for all $k \in \mathbb{N}$.

Then $\mathrm{T}$ has a fixed point.

Proof. The proof follows from Theorem 2.7 by defining $\eta: X \times X \rightarrow \mathbb{R}$ via $\eta(x, y)=1$.

Corollary 2.11. Let $(\mathrm{X}, \mathrm{d})$ be a complete metric space and $\mathrm{T}$ be a mapping on $\mathrm{X}$. Assume that $\alpha: \mathrm{X} \times \mathrm{X} \rightarrow[0, \infty)$ is a function. Suppose that the following conditions hold:

1. If $\alpha(x, y) \geqslant 1$, then $\Rightarrow \psi(d(T x, T y)) \leqslant F(\psi(M(x, y)), \varphi(M(x, y)))$, where

$$
M(x, y)=\max \{d(x, y), d(x, T x), d(y, T y)\}
$$

2. T is triangular $\alpha$-admissible.

3. There exists $\mathrm{x}_{0} \in \mathrm{X}$ such that $\alpha\left(\mathrm{x}_{0}, \mathrm{~T} \mathrm{x}_{1}\right) \geqslant 1$.

4. If $\left\{x_{n}\right\}$ is a sequence in $X$ such that $\alpha\left(x_{n}, x_{n+1}\right) \geqslant 1$ for all $n \in N$ and $x_{n} \rightarrow x^{*}$ as $n \rightarrow \infty$, there exists a subsequence $\left\{x_{n(k)}\right\}$ of $\left\{x_{n}\right\}$ such that $\alpha\left(x_{n(k)}, x^{*}\right) \geqslant 1$ for all $k \in \mathbb{N}$.

Then $(\mathrm{S}, \mathrm{T})$ have a common fixed point.

Proof. The proof follows from Corollary 2.10 by taking $S=\mathrm{T}$.

Remark 2.12. Corollary 2.9 and Corollary 2.11 can be also obtained from Ref. [5].

Corollary 2.13. Let $(\mathrm{X}, \mathrm{d})$ be a complete metric space and $\mathrm{S}, \mathrm{T}$ be self-mappings on $\mathrm{X}$. Assume that $\alpha, \eta: \mathrm{X} \times \mathrm{X} \rightarrow$ $[0, \infty)$ are two functions. Suppose there exist $\mathrm{k} \in[0,1], \psi \in \Psi$ and $\varphi \in \Phi$ such that for all $\mathrm{x}, \mathrm{y} \in \mathrm{X}$ with $\alpha(x, y) \geqslant \eta(x, y)$, we have

$$
\psi(d(S x, T y)) \leqslant k \psi(\max \{d(x, y), d(x, S x), d(y, T y)\}) .
$$

Also, suppose that the following conditions hold: 
1. $(\mathrm{X}, \mathrm{d})$ is an $\alpha, \eta$-complete metric space.

2. The pair $(S, T)$ is triangular $\alpha$-admissible with respect to $\eta$.

3. There exists $\mathrm{x}_{0} \in X$ such that $\alpha\left(\mathrm{x}_{0}, S \mathrm{x}_{1}\right) \geqslant \eta\left(\mathrm{x}_{0}, S \mathrm{x}_{1}\right)$.

4. $S$ and $T$ are $\alpha, \eta$-continuous functions.

Then $\mathrm{S}$ and $\mathrm{T}$ have a common fixed point.

Proof. Define $F: \mathbb{R}^{+} \times \mathbb{R}^{+} \rightarrow \mathbb{R}$ via $F(s, t)=k s$. Note that $F \in \mathcal{C}$. So the pair $(S, T)$ is triangular $\alpha$ admissible. Moreover, the mappings $S, T$ satisfy all the hypotheses of Theorem 2.6. Therefore $S$ and $T$ have a common fixed point.

Corollary 2.14. Let $(X, d)$ be a complete metric space and $\mathrm{S}, \mathrm{T}$ be self-mappings on $\mathrm{X}$. Assume that $\alpha, \eta: \mathrm{X} \times \mathrm{X} \rightarrow$ $[0, \infty)$ are two functions. Suppose there exist $k \in[0,1], \psi \in \Psi$ and $\varphi \in \Phi$ such that for all $x, y \in X$ with $\alpha(x, y) \geqslant \eta(x, y)$, we have

$$
\psi(d(S x, T y)) \leqslant k \psi(\max \{d(x, y), d(x, S x), d(y, T y)\}) .
$$

Also, suppose that the following conditions hold:

1. $(\mathrm{X}, \mathrm{d})$ is an $\alpha, \eta$-complete metric space.

2. The pair $(S, T)$ is triangular $\alpha$-admissible with respect to $\eta$.

3. There exists $\mathrm{x}_{0} \in \mathrm{X}$ such that $\alpha\left(\mathrm{x}_{0}, \mathrm{~S} \mathrm{x}_{0}\right) \geqslant \eta\left(\mathrm{x}_{0}, \mathrm{~S} \mathrm{x}_{0}\right)$.

4. If $\left\{x_{n}\right\}$ is a sequence in $X$ such that $\alpha\left(x_{n}, x_{n+1}\right) \geqslant 1$ for all $n \in N$ and $x_{n} \rightarrow x^{*}$ as $n \rightarrow \infty$, there exists a subsequence $\left\{x_{n(k)}\right\}$ of $\left\{x_{n}\right\}$ such that $\alpha\left(x_{n(k)}, x^{*}\right) \geqslant 1$ for all $k \in \mathbb{N}$.

Then $\mathrm{S}$ and $\mathrm{T}$ have a common fixed point.

Proof. Define $F: \mathbb{R}^{+} \times \mathbb{R}^{+} \rightarrow \mathbb{R}$ via $F(s, t)=k s$. Note that $F \in \mathcal{C}$. So the pair $(S, T)$ is triangular $\alpha$ admissible. Moreover, the mappings $S, T$ satisfy all the hypotheses of Theorem 2.7. Therefore $S$ and $T$ have a common fixed point.

Let $\beta:[0,+\infty) \rightarrow[0,1)$ be a continuous function. Define $F:[0, \infty) \times[0, \infty) \rightarrow[0, \infty)$ via $F(s, t)=s \beta(t)$. Then $\mathrm{F} \in \mathcal{C}$. By Theorem 2.6 and Theorem 2.7, we have the following results:

Corollary 2.15. Let $(\mathrm{X}, \mathrm{d})$ be a complete metric space and $\mathrm{S}, \mathrm{T}$ be two self-mappings on $\mathrm{X}$. Assume that $\alpha$ : $X \times X \rightarrow[0, \infty)$ is a function. Suppose there exist $\psi \in \Psi$ and a continuous function $\beta:[0,+\infty) \rightarrow[0,1)$ such that for all $x, y \in X$ with $\alpha(x, y) \geqslant 1$, we have

$$
\alpha(x, y) \psi(d(S x, T y)) \leqslant \psi\left(M^{*}(x, y)\right) \beta\left(\psi\left(M^{*}(x, y)\right)\right) .
$$

Also, suppose that the following conditions hold:

1. $(\mathrm{X}, \mathrm{d})$ is an $\alpha$-complete metric space.

2. The pair $(\mathrm{S}, \mathrm{T})$ is triangular $\alpha$-admissible.

3. There exists $\mathrm{x}_{0} \in \mathrm{X}$ such that $\alpha\left(\mathrm{x}_{0}, \mathrm{~S} \mathrm{x}_{0}\right) \geqslant \eta\left(\mathrm{x}_{0}, \mathrm{~S} \mathrm{x}_{0}\right)$.

4. $S$ and $T$ are continuous mappings.

Then $\mathrm{S}$ and $\mathrm{T}$ have a common fixed point.

Corollary 2.16. Let $(\mathrm{X}, \mathrm{d})$ be a complete metric space and $\mathrm{S}, \mathrm{T}$ be two self-mappings on $\mathrm{X}$. Assume that $\alpha$ : $X \times X \rightarrow[0, \infty)$ is a function. Suppose there exist $\psi \in \Psi$ and a continuous function $\beta:[0,+\infty) \rightarrow[0,1)$ such that for all $x, y \in X$ with $\alpha(x, y) \geqslant 1$, we have

$$
\alpha(x, y) \psi(d(S x, T y)) \leqslant \psi\left(M^{*}(x, y)\right) \beta\left(\psi\left(M^{*}(x, y)\right)\right) .
$$

Also, suppose that the following conditions hold: 
1. $(\mathrm{X}, \mathrm{d})$ is an $\alpha$-complete metric space.

2. The pair $(\mathrm{S}, \mathrm{T})$ is triangular $\alpha$-admissible.

3. There exists $\mathrm{x}_{0} \in X$ such that $\alpha\left(\mathrm{x}_{0}, S \mathrm{x}_{0}\right) \geqslant \eta\left(\mathrm{x}_{0}, S \mathrm{x}_{0}\right)$.

4. If $\left\{x_{n}\right\}$ is a sequence in $X$ such that $\alpha\left(x_{n}, x_{n+1}\right) \geqslant 1$ for all $n \in N$ and $x_{n} \rightarrow x^{*}$ as $n \rightarrow \infty$, there exist a subsequence $\left\{x_{n(k)}\right\}$ of $\left\{x_{n}\right\}$ such that $\alpha\left(x_{n(k)}, x^{*}\right) \geqslant 1$ for all $k \in \mathbb{N}$.

Then $\mathrm{S}$ and $\mathrm{T}$ have a common fixed point.

Example 2.17. Let $X=(-1,1]$ and $d: X \times X \rightarrow \mathbb{R}$ define by $d(x, y)=|x-y|$ for all $x, y \in X$. Define $\psi, \phi:[0, \infty) \rightarrow[0, \infty)$ by $\psi(t)=t$ and $\phi(t)=\frac{1}{3} \mathrm{t}$. Define the mappings $S, T: X \rightarrow X$ by

$$
\begin{aligned}
& S x= \begin{cases}\frac{x}{3} & \text { if } x \in(-1,0), \\
\frac{x}{9} & \text { if } x \in[0,1]\end{cases} \\
& T x= \begin{cases}\frac{x}{2} & \text { if } x \in(-1,0), \\
\frac{x}{3} & \text { if } x \in[0,1]\end{cases}
\end{aligned}
$$

Also, we define the functions $\alpha, \eta: X \times X \rightarrow[0, \infty)$ by

$$
\begin{aligned}
& \alpha(x, y)= \begin{cases}2 & \text { if } x, y \in[0,1] \\
\frac{1}{5} & \text { if otherwise }\end{cases} \\
& \eta(x, y)= \begin{cases}1 & \text { if } x, y \in[0,1] \\
\frac{1}{3} & \text { if otherwise }\end{cases}
\end{aligned}
$$

We will prove that $(S, T)$ is a generalized F-contraction type mapping.

If $\alpha(x, y) \geqslant \eta(x, y)$, then $x, y \in[0,1]$. Therefore

$$
\begin{aligned}
\psi(d(S x, T y)) & =\left|\frac{x}{9}-\frac{y}{3}\right| \\
& =\left|\frac{x}{9}-\frac{y}{9}-\frac{2 y}{9}\right| \\
& \leqslant\left|\frac{x}{9}-\frac{y}{9}+\frac{2 y}{9}\right| \\
& \leqslant \max \left\{\frac{2}{9}|x-y|, \frac{4}{9} y\right\} \\
& \leqslant \frac{2}{3} \max \left\{|x-y|, \frac{2}{3} y\right\} \\
& =\frac{2}{3} \max \{d(x, y), d(y, T y)\} \\
& \leqslant \frac{2}{3} M^{*}(x, y) \\
& =M^{*}(x, y)-\frac{1}{3} M^{*}(x, y) \\
& =\psi\left(M^{*}(x, y)\right)-\phi\left(M^{*}(x, y)\right) \\
& =F\left(\psi\left(M^{*}(x, y)\right), \phi\left(M^{*}(x, y)\right)\right) .
\end{aligned}
$$

Thus the pair $(S, T)$ is a generalized F-contraction type mapping. Now, we prove that $(X, d)$ is an $\alpha, \eta-$ complete metric space. If $\left\{x_{n}\right\}$ is a Cauchy sequence in $X$ such that $\alpha\left(x_{n}, x_{n+1}\right) \geqslant \eta\left(x_{n}, x_{n+1}\right)$ for all $n \in \mathbb{N}$, then $\left\{x_{n}\right\} \subseteq[0,1]$ for all $n \in \mathbb{N}$. Since $([0,1], d)$ is a complete metric space, then the sequence $\left\{x_{n}\right\}$ converge to $x$ in $[0,1] \subseteq X$. If $\alpha(x, y) \geqslant \eta(x, y)$, then $x, y \in[0,1]$. So $S x, T y, T S x, S T y \in[0,1]$. Therefore 
$\alpha(S x, T y)=2 \geqslant \eta(S x, T y)=1$ and $\alpha(T S x, S T y)=2 \geqslant \eta(T S x, S T y)=1$. Also, if $\alpha(x, z) \geqslant \eta(x, z)$ and $\alpha(z, y) \geqslant \eta(z, y)$, then $x, z, y \in[0,1]$. Thus $\alpha(x, y)=2 \geqslant \eta(x, y)=1$. This implies that the pair $(S, T)$ is triangular $\alpha$-admissible with respect to $\eta$. It is clear that the Condition (4) of Theorem 2.6 is satisfied with $\mathrm{x}_{0}=0 \in X$. So $S \mathrm{x}_{0}=0$. Since

$$
\alpha\left(x_{0}, S x_{0}\right)=\alpha(0,0)=2>1=\eta(0,0)=\eta\left(x_{0}, S x_{0}\right) .
$$

Let $\left\{x_{n}\right\} \subseteq[0,1]$ for all $n \in \mathbb{N}$. This implies that

$$
\lim _{n \rightarrow \infty} S x_{n}=\lim _{n \rightarrow \infty} \frac{1}{9} x_{n}=\frac{1}{9} x=S x
$$

and

$$
\lim _{n \rightarrow \infty} T x_{n}=\lim _{n \rightarrow \infty} \frac{1}{3} x_{n}=\frac{1}{3} x=T x ;
$$

that is, $(S, T)$ is an $\alpha, \eta$-continuous. Thus, all assumptions of Theorem 2.6 are satisfied. Hence $S$ and $T$ have a common fixed point which is $x=0$.

\section{Applications}

In this section, we apply our results to construct an application on Lebesgue-integrable. Denote by $\Gamma$ the set of functions $\lambda: \mathbb{R}^{+} \rightarrow \mathbb{R}^{+}$satisfying the following conditions:

1. $\lambda$ is Lebesgue-integrable on each compact of $\mathbb{R}^{+}$;

2. For each $\epsilon>0$, we have

$$
\int_{0}^{\epsilon} \lambda(z) \mathrm{d} z>0
$$

Theorem 3.1. Let $(\mathrm{X}, \mathrm{d})$ be a complete metric space and $\mathrm{S}, \mathrm{T}$ be two self-mappings on $\mathrm{X}$. Also, let $\mathrm{F} \in \mathcal{F}$ and $\lambda_{1}, \lambda_{2} \in \Gamma$. Assume that $\alpha, \eta: X \times X \rightarrow[0, \infty)$ are two functions such for all $x, y \in X$ with $\alpha(x, y) \geqslant \eta(x, y)$, we have

$$
\int_{0}^{\mathrm{d}(\mathrm{Sx}, \mathrm{Ty})} \lambda_{1}(z) \mathrm{d} z \leqslant \mathrm{~F}\left(\int_{0}^{\mathrm{M}^{*}(x, y)} \lambda_{1}(z) \mathrm{d} z, \int_{0}^{\mathrm{M}^{*}(x, y)} \lambda_{2}(z) \mathrm{d} z\right) .
$$

Also, suppose the following hypotheses:

1. $(\mathrm{X}, \mathrm{d})$ is an $\alpha, \eta$-complete metric space.

2. The pair $(S, T)$ is triangular $\alpha$-admissible with respect to $\eta$.

3. There exists $\mathrm{x}_{0} \in \mathrm{X}$ such that $\alpha\left(\mathrm{x}_{0}, S \mathrm{x}_{0}\right) \geqslant \eta\left(\mathrm{x}_{0}, S \mathrm{x}_{0}\right)$.

4. $S$ and $\mathrm{T}$ are $\alpha, \eta$-continuous functions.

Then $S$, T have a common fixed point.

Proof. Define the functions $\psi, \varphi: \mathbb{R}^{+} \rightarrow \mathbb{R}^{+}$via $\psi(t)=\int_{0}^{t} \lambda_{1}(z) \mathrm{d} z$ and $\varphi(t)=\int_{0}^{t} \lambda_{2}(z) d z$. Noting that $\psi$ is an altering distance function and $\varphi \in \Phi$. So the pair $(S, T)$ is triangular $\alpha$-admissible with respect to $\eta$. So $S$ and $T$ satisfy all the hypotheses of theorem 2.6. Therefore $S$ and $T$ have a common fixed point.

Theorem 3.2. Let $(\mathrm{X}, \mathrm{d})$ be a complete metric space and $\mathrm{S}, \mathrm{T}$ be two self-mappings on $\mathrm{X}$. Also, let $\mathrm{F} \in \mathcal{F}$ and $\lambda_{1}, \lambda_{2} \in \Gamma$. Assume that $\alpha, \eta: X \times X \rightarrow[0, \infty)$ be two functions such for all $x, y \in X$ with $\alpha(x, y) \geqslant \eta(x, y)$, we have

$$
\int_{0}^{\mathrm{d}(\mathrm{Sx}, \mathrm{Ty})} \lambda_{1}(z) \mathrm{d} z \leqslant \mathrm{~F}\left(\int_{0}^{\mathrm{M}^{*}(x, y)} \lambda_{1}(z) \mathrm{d} z, \int_{0}^{\mathrm{M}^{*}(x, y)} \lambda_{2}(z) \mathrm{d} z\right) .
$$

Also, suppose the following hypotheses:

1. $(\mathrm{X}, \mathrm{d})$ is an $\alpha, \eta$-complete metric space.

2. The pair $(S, T)$ is triangular $\alpha$-admissible with respect to $\eta$. 
3. There exists $\mathrm{x}_{0} \in \mathrm{X}$ such that $\alpha\left(\mathrm{x}_{0}, \mathrm{~S} \mathrm{x}_{0}\right) \geqslant \eta\left(\mathrm{x}_{0}, \mathrm{~S} \mathrm{x}_{0}\right)$.

4. If $\left\{x_{n}\right\}$ is a sequence in $X$ such that $\alpha\left(x_{n}, x_{n+1}\right) \geqslant 1$ for all $n \in N$ and $x_{n} \rightarrow x^{*}$ as $n \rightarrow \infty$, there exists a subsequence $\left\{x_{n(k)}\right\}$ of $\left\{x_{n}\right\}$ such that $\alpha\left(x_{n(k)}, x^{*}\right) \geqslant 1$ for all $k \in \mathbb{N}$.

Then $\mathrm{S}$, T have a common fixed point.

Proof. Follow from Theorem 2.7 by Defining $\psi(t)=\int_{o}^{t} \lambda_{1}(z) d z$ and $\varphi(t)=\int_{0}^{t} \lambda_{2}(z) d z$. Noting that the mappings $S$ and T satisfy all the hypotheses of theorem 2.7.

Remark 3.3. Theorem 2.4 of [10] is a special case of our result (Corollary 2.15).

Remark 3.4. Theorem 2.4 of [10] is a special case of our result (Corollary 2.16).

Remark 3.5. Theorem 2.3 of [5] is a special case of our result (Theorem 2.6).

Remark 3.6. Theorem 2.4 of [5] is a special case of of our result (Theorem 2.7).

\section{Acknowledgment}

The authors thank the editor of the paper and the reviewers for their valuable remarks in our paper. Also, the authors would like to acknowledge the grant: UKM Grant DIP-2014-034 and Ministry of Education, Malaysia grant FRGS/1/2017/STG06/UKM/01/1 for financial support.

\section{References}

[1] P. Chuadchawna, A. Kaewcharoen and S. Plubtieng, Fixed point theorems for generalized $\alpha-\eta-\psi-G e r a g h t y$ contraction type mappings in $\alpha-\eta-\psi$-complete metric spaces, J. Nonlinear Sci. Appl., 9 (2016), 471-485. 1.9

[2] S. Alizadeh, F. Moradlou, P. Salimi, Some fixed point results for $(\alpha, \beta)-(\psi, \phi)$-contractive mappings, Filomat, 28 (2014), 635-647. 1, 1

[3] H. Alsamir, M. S. Noorani, W. Shatanawi, F. Shaddad, GeGeneralized Berinde-type $(\eta, \xi, \vartheta, \theta)$ contractive mappings in B-metric spaces with an application, J. Math. Anal., 6 (2016), 1-12. 1

[4] A. H. Ansari, Note on $\varphi-\psi$-contractive type mappings and related fixed point, The 2nd Regional Conference on Mathematics and Applications, Payame Noor University, Tehran, (2014), 377-380. 1, 1.3, 1.4

[5] A. H. Ansari, J. Kaewcharoen, C-class functions and fixed point theorems for generalized $\alpha-\eta-\psi-\varphi-F-c o n t r a c t i o n$ type mappings in $\alpha-\eta$-complete metric spaces, J. Nonlinear Sci. Appl., 9 (2016), 4177-4190. 1, 1, 1.5, 1.8, 2.12, 3.5, 3.6

[6] A. H. Ansari, W. Shatanawi, A. kurdi, G. Maniu, Best proximity points in complete metric spaces with (P)-property via C-class functions, J. Math. Anal., 7 (2016), 54-67. 1

[7] P. Das, L. K. Dey, A fixed point theorem in a generalized metric space, Soochow J. Math., 33 (2007), 33-39. 1, 1

[8] N. Hussain, M. A. Kutbi, P. Salimi, Fixed point theory in $\alpha$-complete metric spaces with applications, Abstr. Appl. Anal., 2014 (2014), 11 pages. 1, 1.6, 1.7

[9] N. Hussain, P. Salimi, A. Latif, Fixed point results for single and set-valued $\alpha-\eta-\psi$-contractive mappings, Fixed Point Theory Appl., 2013 (2013), 23 pages. 1, 1

[10] E. Karapinar, $\alpha-\psi$-Geraghty contraction type mappings and some related fixed point results, Filomat, 28 (2014), 37-48. 3.3, 3.4

[11] E. Karapınar, P. Kumam, P. Salimi, On $\alpha-\psi$-Meir-Keeler contractive mappings, Fixed Point Theory Appl., 2013 (2013), 12 pages. $1,1.2,1$

[12] M. S. Khan, A fixed point theorem for metric spaces, Rend. Ist. Mat. Univ. Trieste, 8 (1976), 69-72. 1

[13] M. S. Khan, M. Swaleh, S. Sessa, Fixed point theorems by altering distances between the points, Bull. Austral. Math. Soc., 30 (1984), 1-9. 1, 1.10

[14] D. K. Patel, T. Abdeljawad, D. Gopal, Common fixed points of generalized Meir-Keeler $\alpha$-contractions, Fixed Point Theory Appl., 2013 (2013), 16 pages. 1, 1

[15] J. R. Roshan, V. Parvaneh, S. Sedghi, N. Shobkolaei, W. Shatanawi, Common fixed points of almost generalized $(\psi, \varphi)_{\mathrm{s}^{-}}$ contractive mappings in ordered b-metric spaces, Fixed Point Theory Appl., 2013 (2013), 23 pages. 1

[16] P. Salimi, A. Latif, N. Hussain, Modified $\alpha-\psi$-contractive mappings with applications, Fixed Point Theory Appl., 2013 (2013), 19 pages. 1,1

[17] B. Samet, C. Vetro, P. Vetro, Fixed point theorems for $\alpha-\psi$-contractive type mappings, Nonlinear Anal., 75 (2012), 2154-2165. 1, 1.1

[18] W. Shatanawi, M. S. Noorani, H. Alsamir, A. Bataihah, Fixed and common fixed point theorems in partially ordered quasi-metric spaces, J. Math. Computer. Sci., 16 (2016), 516-528.

[19] W. Shatanawi, M. Postolache, Common fixed point results for mappings under nonlinear contraction of cyclic form in ordered metric spaces, Fixed Point Theory Appl., 2013 (2013), 13 pages. 1 